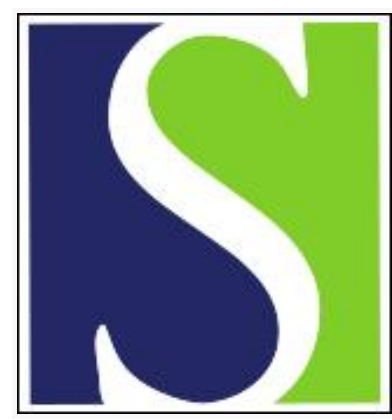

Scand J Work Environ Health 2010;36(4):325-331

https://doi.org/10.5271/sjweh.3062

Published online: 07 Jun 2010, Issue date: 01 Jun 2010

Factors influencing the transferability of occupational safety and health economic incentive schemes between different countries

by Elsler D, Eeckelaert L

Affiliation: European Agency for Safety and Health at Work (EU-OSHA)

Refers to the following text of the Journal: 2007;33(2):85-95

Key terms: cross-cultural differences; discussion paper; economic incentive; economic incentive scheme; economics; external economic incentive; occupational safety and health; $\mathrm{OSH}$

This article in PubMed: www.ncbi.nlm.nih.gov/pubmed/20526536

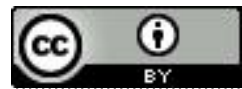




\title{
Factors influencing the transferability of occupational safety and health economic incentive schemes between different countries
}

\author{
by Dietmar Elsler, PhD, ${ }^{1}$ Lieven Eeckelaert, MSc ${ }^{2}$
}

\begin{abstract}
Elsler D, Eeckelaert L. Factors influencing the transferability of occupational safety and health economic incentive schemes between different countries. Scand J Work Environ Health. 2010;36(4):325-331.

Objectives This article looks at the factors that influence the transferability of different types of occupational safety and health (OSH) economic incentives from one country to another.

Methods To review the legal, political, and cultural framework conditions for economic incentive schemes in the European Union (EU), the European Agency for Safety and Health at Work (EU-OSHA) surveyed EU member states about the state of such schemes in their countries. In addition to the survey responses, relevant information on existing schemes and their national context within the $27 \mathrm{EU}$ member states was gathered through reports, articles, and databases. Following this, countries were clustered according to cross-cultural differences.

Results Despite the apparent variations in Europe's social security systems, there is a high degree of similarity between the countries regarding the basic criteria of design of the system. In addition, different kinds of incentives are used in different member states regardless of the social insurance system. When it comes to insurance incentive schemes, the fundamental difference between countries is whether the workers' compensation scheme is based on a competitive market between private insurance companies or a kind of monopoly structure, where the employers do not have the choice between several insurance companies. A clear majority of 19 of the $27 \mathrm{EU}$ member states have a monopoly system.
\end{abstract}

Conclusions Subsidy systems, tax incentives, and insurance-based "experience rating" are theoretically possible in all EU countries. In competitive insurance markets, effort-based incentives are more difficult to achieve. A possible solution could be the introduction of long-term contracts or the creation of a common prevention fund, financed equally by all insurers.

Key terms cross-cultural differences; external economic incentives; OSH.

Economic incentives aim to stimulate enterprises to invest in management of occupational safety and health (OSH) by making it more financially attractive. The European Community strategy on safety and health at work confirms the role of economic incentives as levers for raising awareness and complying with legislation: "The development of awareness may also be reinforced, particularly in [small- and medium-sized enterprises] SMEs, by providing direct or indirect economic incentives for prevention measures. Such incentives could include a possible reduction in social contributions or insurance premiums depending on the investment made in improving the working environment and/or reducing accidents, economic aid for the introduction of health and safety management schemes, and introduction of health and safety requirements into procedures for the award of public contracts" (1).
In recent years, the research discussion about economic incentive schemes has been focussed on the effectiveness of specific incentives (2-4) (ie, how far these schemes can really contribute to better working conditions and less work accidents and occupational diseases). However, if successful incentive schemes are identified, there still remains the question for European policy-makers, if and how such good examples could be transferred from one country to another. Therefore, we analysed the legal and political framework conditions of social insurance and tax systems in the EU member states, in order to understand which kind of economic incentives can be applied in which countries. Furthermore, the scientific literature suggests that cross-cultural differences could also play a role in the transferability of OSH incentive systems $(5,6)$. Trompenaars \& Hampden-Turner (7) emphasize particularly

1 European Agency for Safety and Health at Work (EU-OSHA), Bilbao, Spain.

2 Prevent, Brussels, Belgium.

Correspondence to: Dietmar Elsler, EU-OSHA, Gran Vía 33, E- 48009 Bilbao, Spain. [E-mail: elsler@osha.europa.eu] 
the differences between Eastern and Western Europe, which they describe as being the most important cultural borderline on the continent.

The discussion about economic incentives at European level started in 1995 with a project of the European Foundation for the Improvement of Living and Working Conditions, which resulted in a proposal for a "European model for the improvement of the working environment in Europe" (8). Proposing a central institution for all European economies, the model suggested premium graduation with a bonus system, investment aid, and a marketing label that symbolizes excellence in the working environment. Further developments of this approach (9) included other arms of social insurances, such as health insurance or pension schemes, all of which would benefit from better working conditions.

This harmonization of economic incentives schemes across borders was a sophisticated proposal, but in reality European Union (EU) member states' social welfare systems are too different for the introduction of a standardized model across Europe (10). However, in the context of the economic crisis, there has been renewed discussion on increased collaboration between European social insurance institutions in order to ensure economic stability in the member states. If some national governments would get into serious financial problems or even state bankruptcy, a central European social insurance system could guarantee a minimum of living standard and social security for all citizens (11). Despite the discussions about the possible transferability of economic incentive schemes, several reports from European institutions $(12,13)$ have highlighted the scope for increasing the use of economic instruments in almost all EU countries due to the potential benefits at the workplace.

The primary focus of this article is on economic incentives that come on top of the enforcement of OSH regulations. There are two main types of financial incentives to stimulate employers to invest in making the workplace healthier and safer. The first type of incentive relates to insurance strategies, where employers receive some form of financial support from insurance bodies or reward for efforts to improve OSH and prevent occupational accidents and diseases. The second type relates to tax and funding schemes that are separate from insurance policies, but which aim to promote the same kind of attention to OSH management.

\section{Methods}

In order to enable easy comparison of how economic incentive systems are handled in the various member states, information on the framework conditions of economic incentive schemes in the EU was collected during an EU-OSHA project in cooperation with its Topic Centre OSH (TC-OSH), a consortium of leading European OSH research institutes.

TC-OSH and EU-OSHA jointly drafted a questionnaire that included aspects of the legal and political background in member states. The questionnaires were sent out to the focal point network of EU-OSHA, which consists of national contact institutions nominated by the 27 member states. Eight questionnaires were returned, namely by Austria, the Czech Republic, Denmark, Finland, Lithuania, Poland, Slovakia, and the UK.

Subsequent to the questionnaire survey, relevant information on existing economic incentive schemes and their national context within the $27 \mathrm{EU}$ member states was gathered through reports, articles, and databases. This included information on: (i) the type of social security system of each member state, (ii) the national legal basis and possibilities with regard to economic incentive schemes in the field of $\mathrm{OSH}$, (iii) the national insurance system(s) of occupational accidents and diseases, and (iv) specific national examples of insurance-based incentives and tax and funding schemes. Some reports from EU-OSHA $(4,14)$, the National Confederation of Greek Trade Unions (proceedings from European Colloquium: Professional risk insurance systems in the candidate countries; Piraeus, Greece; 3-5 April 2003), and the Mutual Information System on Social Protection (MISSOC) database (15) were particularly useful, as well as Münchener Rückversicherungs-Gesellschaft (Munich RE Group, a reinsurance company) (16-19). Where necessary, information was checked with contact persons and experts in the respective member states.

In a next phase, we analyzed all collected material with the aim of extracting and clustering common characteristics with regard to the social security systems and accident insurance schemes of the member states. European social security and healthcare systems can, on the basis of their financing sources, generally be categorized into two main types: "Beveridgian" and "Bismarckian" $(20,6)$. Whereas the Beveridge model is financed by tax, the Bismarckian model is funded by social insurance (contributions). The majority of social security systems in the EU are primarily contributionsbased, although there has never been a pure system of either type (21).

Insurance schemes against occupational accidents and diseases in the EU can be categorized into public (state-run) and private (run by private insurance companies) workers' compensation schemes. In a public system, workers' compensation is integrated into a social security administration or organized into a separate unit (eg, a special fund). In a private system, insurance companies act as main players in a privatized market 
with compulsory insurance, covering the risks and offering the benefits prescribed by law. Furthermore, a distinction can be drawn between state monopolies on the one hand, and private, free markets for workers' compensation insurance on the other. In the latter case, there may be restrictions to the free market (eg, with regard to the insurance of occupational diseases).

The ultimate objective of this categorization was to get a view on which economic incentives in $\mathrm{OSH}$ are applied in which context (social insurance system), and whether certain incentives could be transferred to countries with similar system characteristics. This classification of accident insurance schemes and social security systems can be put in a broader perspective of welfare systems. Different welfare models rely on different traditions of industrial and other social relations, and each has a specific institutional structure of welfare benefits provision. The most influential typology in this regard is that of Esping-Andersen (22), which distinguishes between three main types of ideal-typical welfare-state regimes: (i) liberal (mainly Anglo-Saxon countries), (ii) conservative-corporatist (mainly the continental or Central European countries), and (iii) social-democratic regimes (mainly the Scandinavian countries). This typology assumes that each welfare system type has a specific ideological and cultural base (including religion) (23).

In order to try to link cultural characteristics and foundations of the member states to the welfare and social security system categorization, some outcomes of the Global Leadership and Organizational Behavior Effectiveness (GLOBE) research program (24) were analyzed and included in this analysis. The GLOBE project was an ambitious project to study the relationship of culture to concepts of leadership. A team of 170 researchers worked together to investigate societal and organizational culture and attributes of effective leadership in 62 cultures. The study was based on a survey of more than 17000 middle managers from three sectors: financial services, food processing, and telecommunications. Based on empirical data, ten worldwide clusters of culturally similar countries were found. For our study, the five European clusters have been applied: (i) Anglo Europe (the UK and Ireland); (ii) Eastern Europe (Hungary, Poland, and Slovenia); (iii) Latin Europe (France, Italy, Portugal, and Spain); (iv) ordic Europe (Denmark, Finland, and Sweden); and (v) Germanic Europe (Austria, Germany (former East and West), and Netherlands.

Unfortunately, the GLOBE study did not cover all EU countries and therefore not all member states could be included in the analysis of cross-cultural differences. Furthermore, some of the European clusters contained non-EU countries (eg, Switzerland was included in the Germanic cluster), which are not covered in our research.

\section{Results}

The results of the survey and analysis are summarized in table 1. The social security systems in Europe are either predominantly Beveridgean (11 countries, mainly tax-based contributions) or Bismarckian (16 countries, mainly insurance-based contributions). The second criterion specifically concerns the accident insurance system, which is either a state-run monopoly (19 countries) or a private competitive market (8 countries). In the EU's 27 member states, there are two dominating models; mostly we have a state-run monopoly with a Bismarckian tradition (14 countries) or a competitive market in a Beveridgean system ( 6 countries). There are also several mixed forms with a Beveridgean system predominating ( 5 countries) and a competitive market in a Bismarckian system (Belgium and the Netherlands).

In several EU countries (Denmark, Estonia, Greece, Spain, Sweden, and the UK) insurance-based incentives (ie, incentives relating to insurance tariffs) do not exist.

Table 1. Overview of social security and incentives systems by country. $[\mathrm{BE}=$ Beveridgean; $\mathrm{BI}=$ Bismarckian; $\mathrm{SM}=$ state-run monopoly; $\mathrm{PC}$ = private competitive market]

\begin{tabular}{|c|c|c|c|c|c|c|}
\hline Country & $\begin{array}{l}\text { Social } \\
\text { security } \\
\text { system }\end{array}$ & $\begin{array}{c}\text { Accident } \\
\text { insurance }\end{array}$ & $\begin{array}{l}\text { Cultural } \\
\text { cluster }\end{array}$ & $\begin{array}{l}\text { Insurance } \\
\text { incentives }\end{array}$ & $\begin{array}{c}\text { Tax } \\
\text { related }\end{array}$ & $\begin{array}{l}\text { Fund- } \\
\text { ing }{ }^{a}\end{array}$ \\
\hline Ireland & $\mathrm{BE}$ & SM & Anglo & & & \\
\hline United Kingdom & $\mathrm{BE}$ & PC & Anglo & & & \\
\hline Greece & $\mathrm{BE}$ & SM & Eastern & & & \\
\hline Hungary & $\mathrm{BI}$ & SM & Eastern & Planned & & \\
\hline Poland & $\mathrm{BI}$ & SM & Eastern & Yes & & Yes \\
\hline Slovenia & $\mathrm{BI}$ & SM & Eastern & & & \\
\hline Germany & $\mathrm{BI}$ & SM & Germanic & Yes & Yes & Yes \\
\hline The Netherlands & $\mathrm{BI}$ & PC & Germanic & Yes & Yes & Yes \\
\hline Austria & $\mathrm{BI}$ & SM & Germanic & & & Yes \\
\hline Spain & $\mathrm{BE}$ & $P C$ & Latin & Planned & & Yes \\
\hline France & $\mathrm{BI}$ & SM & Latin & Yes & & Yes \\
\hline Italy & BE & SM & Latin & Yes & & Yes \\
\hline Portugal & $\mathrm{BE}$ & $P C$ & Latin & Yes & & \\
\hline Denmark & $\mathrm{BE}$ & $P C$ & Nordic & & & Yes \\
\hline Finland & $\mathrm{BE}$ & PC & Nordic & Yes & & Yes \\
\hline Sweden & $\mathrm{BE}$ & SM & Nordic & & & \\
\hline Belgium & $\mathrm{BI}$ & $\mathrm{PC}$ & & Yes & & Yes \\
\hline Bulgaria & $\mathrm{BI}$ & SM & & Yes & & Yes \\
\hline Czech Republic & $\mathrm{BI}$ & SM & & Yes & & \\
\hline Estonia & $\mathrm{BI}$ & SM & & & & \\
\hline Cyprus & BE & PC & & & & \\
\hline Latvia & $\mathrm{BI}$ & SM & & & Yes & \\
\hline Lithuania & $\mathrm{BI}$ & SM & & & & Yes \\
\hline Luxembourg & $\mathrm{BI}$ & SM & & Yes & & Yes \\
\hline Malta & $\mathrm{BE}$ & SM & & & & \\
\hline Romania & $\mathrm{BI}$ & SM & & & & \\
\hline Slovak Republic & $\mathrm{BI}$ & SM & & & & \\
\hline
\end{tabular}

a Subsidies or grants. 
In these countries, insurance premiums may be set, for example, using a risk category system for different sectors and occupations. Methods for setting risk category premiums cannot, however, be regarded as true economic incentives as they differentiate the insurance premium only for a group of enterprises, but not on an individual corporate level to motivate an enterprise to improve OSH. Other EU countries (Belgium, Bulgaria, Czech Republic, Germany, France, Italy, the Netherlands, Poland, Portugal, and Finland), have a type of economic incentive where premium variation is based on "experience rating" (ie, pricing premiums for different groups or individuals based on the group or individual's history of claims otherwise known as the bonus-malus system). An additional way of persuading employers to invest in $\mathrm{OSH}$ is through insurance-related incentives, where specific prevention efforts are rewarded according to a predetermined model. Such approaches exist, for example, in Germany (which has a sectoral occupational insurance approach), and the Netherlands (specific insurance-related incentives are set within the framework of contracts between employers, private insurers, and safety and health services). In some countries, (eg, Belgium, France, Poland, and Finland), company size is taken into account when setting insurance premiums. France and Finland also have different premium systems for larger and smaller companies.

Although insurance-related economic incentives are quite common in Europe (3) to promote the prevention of accidents and diseases in the workplace, they are not the only alternative and should, therefore, be regarded as a single strategy within a group of initiatives, including tax incentives and funding schemes. Tax-related incentives in $\mathrm{OSH}$ are very rare within the EU. Funding schemes for OSH, on the other hand, are found in nearly every EU country. Funds (subsidies, grants) are provided for a wide range of practices, from the purchase of certain materials and tools to the implementation of OSH management systems. These funding schemes are established mainly by public bodies.

When looking at the different cultural clusters in Europe, some characteristics of the clusters regarding economic incentives can be identified. In the Anglo cluster, incentives for OSH are not implemented at all. Whereas all Latin European countries employ subsidy

Table 2. Values of cultural dimensions in different clusters. [1 = low; 7 = high]

\begin{tabular}{lccccc}
\hline Cultural dimensions & Germanic & Eastern & Anglo & Latin & Nordic \\
\hline Uncertainty avoidance & 5.12 & 3.56 & 4.42 & 4.18 & 5.19 \\
Future orientation & 4.40 & 3.37 & 4.08 & 3.68 & 4.36 \\
Power distance & 3.47 & 4.22 & 4.23 & 3.86 & 3.63 \\
Gender egalitarianism & 3.14 & 3.84 & 3.40 & 3.36 & 3.71 \\
\hline
\end{tabular}

schemes and most of them also offer insurance schemes. The other clusters show a more mixed picture. In the Germanic countries, Dutch and German economic incentives play an important role as a policy instrument to promote OSH, whereas in Austria only subsidy schemes are applied. Among the Eastern European countries, only Poland applies incentives as a macroeconomic instrument; among the Nordic countries, Finland makes most use of incentives.

To discuss the possible influence of cultural dimensions on the use of incentive schemes we have to take a closer look at the cultural characteristics of each cluster. Table 2 shows the values of several cultural dimensions, which we have chosen from the GLOBE study (24) and assume have a possible influence on $\mathrm{OSH}$ : (i) uncertainty avoidance: the extent to which a society, organization, or group relies on social norms, rules, and procedures to alleviate unpredictability of future events; (ii) future orientation: the extent to which individuals engage in future-oriented behaviors such as delaying gratification, planning, and investing in the future; (iii) power distance: the degree to which members of a collective expect power to be distributed equally; (iv) gender egalitarianism: the degree to which a collective minimizes gender inequality.

The Nordic and Germanic countries are characterized by a high degree of uncertainty avoidance and a high future orientation. This could be beneficial for $\mathrm{OSH}$ as there is a lower tendency to take risks, and many investments in the improvements of working conditions pay out only long- rather than short-term. The Anglo, Eastern and Latin clusters have a lower extent of uncertainty avoidance and future orientation. Subsequently, there is a less of a tendency to regulate $\mathrm{OSH}$, instead there is probably a greater preference for more individual solutions on a corporate level.

The dimension of power distance can be applied to the relation of workers and managers. A lower power distance is generally associated with less autocratic leadership style and more worker involvement. In countries with lower power distance, such as the Nordic, Latin and Germanic clusters, it will probably be easier to engage workers and use their creative potential in order to ensure effective OSH management. High values of gender egalitarianism, such as in the Eastern cluster, show that specific work-related risks of women are considered better in the workplace and that they participate equally in decision-making processes.

\section{Discussion}

Regarding the basic criteria of social insurance systems and worker's compensation approaches, there are not very many differences in Europe. Most countries 
designed their social security system in the Bismarckian tradition and the accident insurance institutions are based on a state-run monopoly. There is a significant group of countries with a competitive market in a Beveridgean system and two smaller groups of countries with mixed forms. So the variety of different accident and social insurance systems is fairly limited regarding basic criteria, even though there are probably many more differences in detail.

The analysis reveals that examples of economic incentives exist in most EU member states. Some countries appear to implement economic incentives as a macroeconomic instrument to improve the quality of the working conditions because they are using a great variety of economic incentives. As shown in table 1, nearly all larger member states, except the UK, are rather active in offering economic incentives. France, Germany, Italy, and Poland all offer various incentives through their public insurance system, often not only insurance premium variations, but also subsidy programs for specific investments in OSH. In Spain, insurance incentives are planned as part of the national OSH strategy and a great variety of OSH subsidy programs are offered on a national as well as regional level. Of the smaller member states, Belgium, Finland, and the Netherlands are the most active, showing that economic incentives are also possible in private accident insurance systems.

We have identified some characteristics of cultural clusters regarding economic incentives in OSH. These results are in line with other findings (6) that stress the role of cultural differences in relation to risks and their prevention. It seems that prevention is more acceptable in risk-adverse (Nordic and Germanic clusters) than riskprone countries (Latin and Eastern clusters). Furthermore, there are variations in attitudes towards $\mathrm{OSH}$ and safety culture that may affect the perception of prevention and illness. Hämäläinen (6) comes to the conclusion that social democratic (ie, Finland, Sweden, Denmark) and insurance-based welfare states (Germany, Austria, the Netherlands) tend to be risk-adverse. Whereas more riskprone countries prefer to have a mix of public and private welfare state services (Italy and Greece), or their welfare state services are funded through taxation and social security or privately (Spain and Portugal).

From our analysis, and taking into account the findings of additional research, we can reasonably assume that cross-cultural differences would play a certain role in the transferability of incentive schemes. However, they are surely not the only predictor for the use of economic incentives, as some cultural clusters are relatively heterogeneous. Therefore more research is needed on how legal, political, economic, and cultural factors interact to make successful incentive schemes possible. Maybe also the dimensions identified by the GLOBE project are too general, as they were developed to describe the cross-cultural differences of management attitudes and behavior. Possibly more specific dimensions could be developed for the OSH area. However, these dimensions were the most applicable and current for this research, and we think they are a good starting point in order to discuss the potential influence of crosscultural dimensions in $\mathrm{OSH}$.

When it comes to economic incentive schemes, the fundamental difference between countries is whether the workers' compensation scheme is based on a competitive market between private insurance companies or a kind of monopoly structure, where the employers do not have the choice between several insurance companies. Regarding this criteria, a clear majority of 19 of the $27 \mathrm{EU}$ member states have opted for a monopoly system. It is beyond the scope of this article to discuss the advantages and drawbacks of the various accident insurance systems. However, it is important to analyze how these differences can influence the possibility of economic incentives.

Insurance premium differentiations in the form of experience rating are possible in all systems. In a competitive market it is even argued that experience rating could strengthen the competition between insurance companies, as they are forced to offer more individual premium rates (25). However, it becomes difficult for insurers in a competitive market to offer rewards for specific prevention activities, such as training, investment in OSH-friendly equipment or the certification of OSH management systems. Subsidizing these preventive activities can be regarded as an investment by the insurance company, which it hopes will pay off in future years when fewer claims should be received. However, in a competitive system, enterprises are able to change their insurance providers at short notice and an insurance company runs the risk that a subsidized client may change to another, possibly cheaper, competitor, after having enjoyed the incentives and consultancy provided by the original insurer.

Investments in health and safety usually pay off only after a longer period of time and this contradicts, to some extent, employers' freedom of access to insurance companies in a market-based system. A possible solution could be the introduction of more long-term contracts, but it may be difficult to persuade employers to give up their freedom of choice. Another possibility would be that all private insurance companies would contribute equally to a common prevention fund that would subsidize clients' OSH activities. By financing the prevention activities this way, companies that change their insurance provider would not receive an unfair advantage, as the fund would have been financed by all insurance companies. Some countries with a private insurance market have already developed such a model (eg, the work environment fund in Finland). 
In monopoly structures, the problem of changing clients does not exist. Enterprises have to stay with the same insurance company and hence it is guaranteed that the insurer will benefit from better prevention among its clients. In this regard, it is much easier in a monopoly system to offer incentives that reward prevention efforts as well as results. Furthermore, accident insurances in a monopoly system frequently are non-profit organizations and have the public mandate to promote prevention among enterprises, so that monopoly and non-profit structures are interlinked.

The challenge is rather to find out which OSH activities are most likely to deliver a significant improvement in OSH performance in the future, and at the same time are relatively easy to control. As the insurer is subsidizing these activities, there is the possibility for the system to be abused in that companies could try to claim for activities that in fact have not been carried out. Case studies collected by EU-OSHA (26) provide an overview of how such approaches can be successfully managed, whether in an insurance-related or a state-run subsidy system.

Our overview shows that insurance-based incentives are quite common in Europe, but that in some countries they do not exist at all (Denmark, Estonia, Greece, Spain, Sweden, and the UK), whereas subsidy schemes are used in nearly all member states. It is also apparent that some countries without any insurance incentives offer, as a kind of compensation, more public subsidy schemes (eg, Spain and Denmark). Therefore, it could be useful for future research to discuss which of these incentive approaches best serves to achieve high levels of OSH.

\section{Concluding remarks}

The differences between countries and economic incentive schemes naturally have an influence on the potential transferability of incentives models in OSH. Subsidy systems and tax incentives theoretically should be possible in all EU countries. Regarding insurance incentives, it is useful to distinguish between two major groups of countries with a different workers' compensation approach: 19 countries have a monopoly structure regarding the accident insurance scheme and 8 have a private competitive insurance market. Experience rating approaches can be found in both competitive and monopolistic markets. However, there are differences when it comes to the funding of future-oriented prevention efforts, such as training or OSH investments. This should be no problem for monopolistic approaches, because the insurance company can be sure it will benefit from the positive effect that investments will have on the claims rate. In a competitive market, however, the insurance company runs the risk that enterprises could change their insurance provider at short notice and investments in prevention efforts could, therefore, benefit its competitors rather than the original insurer. A possible solution for competitive markets could be the introduction of long-term contracts over several years or the creation of a common prevention fund which is financed equally by all insurers.

Although we have some support for the assumption that cross-cultural differences can play a role regarding the transferability of economic incentives, more research is needed to analyze how this factor would influence exactly the application of incentive schemes.

\section{Acknowledgements}

This article is based on an EU-OSHA project about economic incentive schemes in Europe. Therefore, we would like to thank the economic incentives expert group and all European partners as well as EU-OSHA and TC-OSH working environment staff who contributed to project.

\section{References}

1. European Commission. Improving quality and productivity at work: community strategy 2007-2012 on health and safety at work. Brussels: European Commission; $\operatorname{COM}(2007) 62$ final. Available from: http://eur-lex.europa.eu/LexUriServ/ LexUriServ.do?uri=COM:2007:0062:FIN:en:PDF

2. Tompa E, Trevithick S, McLeod C. A systematic review of the prevention incentives of insurance and regulatory mechanisms for occupational health and safety. Scand J Work Environ Health. 2007;33(2):85-95.

3. Elsler D, Treutlein D, Rydlewska I, Frusteri L, Krüger H, Van Den Broek K, et al. A review of case studies evaluating economic incentives to promote occupational safety and health. Scand J Work Environ Health. 2010;36(4):289-298.

4. European Agency for Safety and Health at Work. Forum 14 effectiveness of economic incentives to improve occupational safety and health [Internet]. European Agency for Safety and Health at Work; 2005 [cited 12 February 2010]. Available from: http://osha.europa.eu/en/publications/forum/14/view

5. Elsler, D. Interkulturelle Aspekte der steigenden Arbeitsmigration zwischen Ost- und Westeuropa und deren Auswirkungen auf den Arbeits- und Gesundheitsschutz [Intercultural aspects of increasing worker migration between Eastern and Western Europe and its effects on occupational safety and health]. In: Gesellschaft für Arbeitswissenschaft, editor. Innovation für Arbeit und Organisation [In: Ergonomic Society, editor. Innovation for work and organisation]. Dortmund (Germany): GfA-Press; 2006. p 267-70.

6. Hämäläinen R-M. The Europeanisation of occupational health services - a study of the impact of EU policies. People and 
Work. Research Reports 82. Helsinki (Finland): Finnish Institute for Occupational Health; 2008, p403.

7. Trompenaars F, Hampden-Turner C. Riding the waves of culture. Understanding cultural diversity in Business. London: Nicholas Brealy; 1997.

8. Bailey S, Jorgensen K, Koch C, Krüger W, Litske H. An innovative economic incentive model for improvement of the working environment in Europe. Dublin: European Foundation for the Improvement of Living and Working Conditions; 1995.

9. Krüger W, Heß D, Müller P, Stegemann K. Wirtschaftliche Anreize für betriebliche Maßnahmen zur Unfallverhütung und zur Verringerung arbeitsbedingter Gesundheitsgefahren [Economic incentives for occupational measures for accident prevention and for the reduction of health hazards]. Bremerhaven (Germany): Wirtschaftverlag NW; 2000.

10. Elsler D, Nikov A. European approaches for economic incentives in occupational safety and health. In: Strasser H, Kluth K, Rausch H, Bubb H, editors. Quality of work and products in enterprises of the future. Stuttgart (Germany): Ergonomia Verlag; 2003.

11. Enderlein H. Nationale Wirtschaftspolitik in der europäischen Währungsunion [National economic policy in the European currency union] [Internet]. Frankfurt (Germany): Campus; 2004 [cited 17 may 2010]. Available from: http://www.mpifg. de/pu/mpifg_book/mpifg_bd_49.pdf

12. Clinch JP, Convery FJ, Fitzgerald E, Rooney SM. Economic instruments for sustainable development: improving the external and working environments. Luxembourg: Office for Official Publications of the European Communities; 2000.

13. Elsler D. European comparison of economic incentives in occupational safety and health. In: Berlin C, Bligård L-O, editors. Proceedings of the 39th Nordic Ergonomics Society Conference; 1-3 October 2007; Lysekil, Sweden. Gothenburg (Sweden); Chalmers University of Technology; 2007.

14. European Agency for Safety and Health at Work. Workrelated musculoskeletal disorders: back to work report [Internet]. Luxembourg: Office for Official Publications of the European Communities; 2007 [cited 12 February 2010]. Available in English at: http:/osha.europa.eu/en/publications/ reports/7807300/view

15. European Commission. MISSOC - Mutual Information System on Social Protection database [Internet]. European Commission [cited 12 February 2010]. Available from: http://ec.europa.eu/employment_social/missoc/db/public/ compareTables.do?lang=en
16. Münchener Rückversicherungs-Gesellschaft (Munich Re Group). Workers' compensation - analysis of private and public systems. Munich (Germany): Munich Re Group; 2000.

17. Münchener Rückversicherungs-Gesellschaft (Munich Re Group). Rating systems - an international comparison of workers' compensation insurance. Munich (Germany): Munich Re Group; 2002.

18. Münchener Rückversicherungs-Gesellschaft (Munich Re Group) Centre of Competence for Workers' Compensation. Economic incentives - a reflection on workers' compensation systems' [Discussion paper]. Munich (Germany): Munich Re Group; 2005.

19. Münchener Rückversicherungs-Gesellschaft (Munich Re Group). To prevent or to insure? 3rd International Workers' Compensation Symposium. Munich (Germany): Munich Re Group; 2007.

20. Figueras J, McKee M, Mossialos E, Saltman R. Social health insurance systems in western Europe [Internet]. Geneva: World Health Organization, Open University Press; 2004 [cited 17 May 2010]. European Observatory on Health Systems and Policies Series. Available from: http://www.euro. who.int/document/E84968.pdf

21. Heikkilä M, Kuivalainen S. Using social benefits to combat poverty and social exclusion - opportunities and problems from a comparative perspective. Strasbourg: Council of Europe; 2002. Trends in Social Cohesion, 3.

22. Esping-Andersen G. The three worlds of welfare capitalism. Cambridge (United Kingdom): Polity Press; 1990.

23. van Oorschot W. Culture and social policy: a developing field of study. Int J Soc Welfare. 2007;16:129-39.

24. House RJ, Hanges PJ, Javidan M, Dorfman PW, Gupta V, editors. Culture, leadership, and organizations: the GLOBE Study of 62 Societies. London: SAGE; 2004.

25. Clayton A. The prevention of occupational injuries and illness: the role of economic incentives [Internet]. Melbourne: National Research Centre for OHS Regulation; 2002 [cited 12 February 2010]. Working paper 5. Available from: http:// dspace.anu.edu.au/bitstream/1885/41128/2/working_paper_5. pdf

26. Elsler D, Taylor TN, editors. Economic incentives to improve occupational safety and health: a review from the European perspective. Luxembourg: Publications Office of the European Union. In press.

Received for publication: 15 February 2010 